\title{
Chipping away at major depressive disorder
}

\author{
James JH Rucker ${ }^{*}$ and Peter McGuffin
}

\begin{abstract}
An intriguing recent study examines the role of miR1202, a glutamate receptor regulating microRNA, in regulating major depressive disorder.
\end{abstract}

\section{The challenge of major depressive disorder}

Major depressive disorder (MDD), a common, yet debilitating and economically costly, psychiatric disorder [1], has proven surprisingly refractory to molecular-genetic investigation and the development of biomarkers for diagnosis and treatment. However, although there was initial excitement over positive findings in studies of genetic linkage [2], genome-wide association of singlenucleotide polymorphisms (SNPs) [3] and copy-number variants [4], none of these areas of investigation has resulted in replicated findings, and a recent genome-wide mega-analysis of SNPs was entirely negative [5]. Similarly, no biomarker for MDD has been found to be clinically useful, despite the pressing need in psychiatry for objective tests for diagnosis and treatment response. The usual genetic model that is used to explain liability in complex disorders is one of polygenic heterogeneity [6], with many variants of small effect co-acting to produce a liability to psychiatric disorders that develops over the lifetime in interplay with the environment. Such a model was first postulated for common psychiatric disorders nearly a half-century ago [7] and has proved to be enduring. However, it remains a general theory that is 'agnostic' about what the component polygenes might be.

In search of further specific elements of the genome that could help explain the heritability of common psychiatric disorders, the role of microRNAs (miRNAs) has recently been investigated. Within mammals, it is estimated that $60 \%$ of all protein-coding genes are regulated by miRNAs, contributing widely to the regulation of most cellular biochemical processes [8]. In addition, miRNAs are found in plasma and might be useful as

\footnotetext{
* Correspondence: james.rucker@kcl.ac.uk

MRC Social, Genetic and Developmental Psychiatry (SGDP) Centre, The

Institute of Psychiatry, Kings College London, 16 De Crespigny Park, London SE5 8AF, UK
}

biomarkers [9] - thus, they are particularly relevant candidates for study in psychiatric disorders. MDD tends to develop after the onset of puberty, with a peak in incidence during early adult life, and a particular preponderance for the female sex. This might suggest regulatory biological elements that segregate by sex and occur at specific points in time during development.

Recently, Lopez and colleagues have published a thought-provoking article in Nature Medicine that implicates a particular miRNA in the development of MDD [10]. The study provides evidence from a number of different experimental paradigms that miR-1202 exists in a dose-dependent relationship with expression of the gene GRM4 (encoding metabotropic glutamate receptor 4) in the human prefrontal cortex and that the expression of miR-1202 is related to successful antidepressant treatment.

\section{miR-1202 is differentially expressed in patients with depression} psychiatrically healthy control samples. The levels of miR-1202 expression were significantly decreased in brains from depressed individuals when compared with those of controls. Psychiatric diagnosis was made postmortem, based on medical records. An in silico investiof evolutionary conservation of miR-1202 across genomes of 100 animal species revealed that miR2 is present only in humans and primates. To conthis finding experimentally, Lopez and colleagues species: human, cynomolgus monkey (Macaca (Mus musculus) and chicken (Gallus gallus) [10]. The authors showed that miR-1202 was not found in rat, mouse and chicken brain but was found in primate brains, with the highest levels in human brain, which also had higher levels than in 10 other investigated forms of human tissue. To predict the functional consequence of miR-1202, the authors used five 
different miRNA target-prediction databases to generate potential gene targets, cross-referencing these with genes expressed and upregulated in the prefrontal cortices of subjects with depression. Of five potential genes, miR-1202 was found to correlate negatively only with expression of GRM4, encoding subtype four of the metabotropic glutamate receptor. In a replication analysis, the authors measured the expression of miR-1202 and GRM4 in an independent sample of human prefrontal cortices that also included depressed individuals who were taking antidepressants at the time of death. Replicating their original findings, the authors also noted that miR-1202 levels were no different between controls and depressed individuals taking antidepressants, suggesting that not only are the levels of miR-1202 inversely related to the level of GRM4 expression, but also that antidepressants modulate the levels of miR-1202 to affect GRM4 expression.

\section{Chronic antidepressant administration upregulates miR-1202}

To investigate this modulatory effect further, human embryonic kidney (HEK) cells were used to perform functional experiments investigating the interaction between miR-1202, GRM4 expression and antidepressants. HEK cells were used because they particularly express GRM4 without expressing miR-1202. Treatment of HEK cells with a miR-1202 mimic resulted in a decreased expression of GRM4, and co-treatment with the miR-1202 mimic together with an agent that interfered with the predicted binding sites of miR-1202 to the transcribed GRM4 mRNA resulted in GRM4 expression levels returning to baseline. Further investigation of the relationship between miR-1202 and GRM4 with agonists and antagonists of GRM4 in neural progenitor cells (NPCs) suggested that miR-1202 exists in a bidirectional relationship with GRM4 expression. To investigate the effects of antidepressants on this relationship, the authors treated NPCs (which show a serotonergic profile) with the archetypal tricyclic antidepressant imipramine, the selective serotonin reuptake inhibitor (SSRI) antidepressant citalopram or a control possessing no active drug. Although there was no effect of acute (24 hours) treatment with either drug on miR-1202 levels or GRM4 expression, chronic treatment (15 days) with either drug resulted in an up-regulation of miR-1202 - findings that were also confirmed using immunohistochemistry. Of note, this effect was not observed when treating cells with the drugs valproate or lithium, neither of which has a direct effect on the sodium-dependent serotonin transporter (SERT). Knockdown experiments showed that the increase in miR-1202 concentrations is dependent on SERT and the reuptake blockade elicited by conventional antidepressants. To rule out global miRNA dysregulation as an explanation of the observed effects, the authors additionally measured the expression levels of miRNAs known to be ubiquitously expressed, but found no differences in expression after chronic antidepressant treatment.

To confirm these findings in vivo, the authors measured blood levels of miR-1202 in treatment-naïve patients with MDD and healthy controls. The levels of mir-1202 were found to be decreased in patients with depression. Patients were then treated with citalopram for eight weeks and classified as responders or nonresponders on the basis of relative changes in Hamilton Depression (HAM-D) rating-scale scores. Although those who achieved remission from symptoms as specified by the HAM-D score showed increased miR-1202 levels after eight weeks of treatment with citalopram, there was no difference in expression in miR-1202 levels between non-responders and psychiatrically healthy controls without major depressive disorder. The change in depression severity, as defined by HAM-D scores, was negatively correlated with miR-1202 expression levels.

\section{Concluding remarks}

This paper presents a striking investigative narrative, providing evidence from a number of different angles that a specific miRNA is a biologically plausible biomarker for detection of, and treatment response in, MDD and is potentially of considerable interest to the relevant research and clinical communities. However, it is sensible to urge caution in such circumstances. It would indeed be a remarkable finding if such a clinically and biologically heterogeneous disorder as MDD was reducible, even in part, to a single biological entity, and one might have expected indications towards this previously. The glutamate system is the major excitatory neurotransmitter in the brain, and it would be unsurprising to find biological links to MDD within it, but certainly surprising to find that molecular regulation of a particular subtype of glutamate receptor was associated with something as conceptually distant as the HAM-D score, a clinically applied measure of subjectively experienced symptoms and observable clinical signs in MDD. Genetic investigation into MDD has failed to explain why significant heritability figures are obtained in twin studies, but a tagging SNP would be expected to achieve genome-wide levels of statistical significance in mega-analyses of MDD [5] if any particular genetic or epigenetic explanation contributed very significantly to the disorder - although there are likely also to be exceptions to this observation. Overall, these provocative and interesting results will certainly require independent replication - however, they present a potentially novel and intriguing facet of the complex genetics of MDD. 


\section{Competing interests}

PM has received consultancy fees and honoraria for participating in expert panels for pharmaceutical companies, including GlaxoSmithKline and Pfizer JR declares no competing interests.

Published online: 26 July 2014

\section{References}

1. Üstün TB, Ayuso-Mateos JL, Chatterji S, Mathers C, Murray CJL: Global burden of depressive disorders in the year 2000. Br J Psychiatry 2004, 184:386-392.

2. Breen G, Webb BT, Butler AW, van den Oord EJCG, Tozzi F, Craddock N, Gill M, Korszun A, Maier W, Middleton L, Mors O, Owen MJ, Cohen-Woods S, Perry J, Galwey NW, Upmanyu R, Craig I, Lewis CM, Ng M, Brewster S, Preisig M, Rietschel M, Jones L, Knight J, Rice J, Muglia P, Farmer AE, McGuffin P: A genome-wide significant linkage for severe depression on chromosome 3: the depression network study. Am J Psychiatry 2011, 168:840-847.

3. Sullivan PF, de Geus EJC, Willemsen G, James MR, Smit JH, Zandbelt T, Arolt V, Baune BT, Blackwood D, Cichon S, Coventry WL, Domschke K, Farmer A, Fava M, Gordon SD, He Q, Heath AC, Heutink P, Holsboer F, Hoogendijk WJ, Hottenga JJ, Hu Y, Kohli M, Lin D, Lucae S, Macintyre DJ, Maier W, McGhee KA, McGuffin P, Montgomery GW, et al: Genome-wide association for major depressive disorder: a possible role for the presynaptic protein piccolo. Mol Psychiatry 2009, 14:359-375.

4. Rucker JJH, Breen G, Pinto D, Pedroso I, Lewis CM, Cohen-Woods S, Uher R, Schosser A, Rivera M, Aitchison KJ, Craddock N, Owen MJ, Jones L, Jones I, Korszun A, Muglia P, Barnes MR, Preisig M, Mors O, Gill M, Maier W, Rice J, Rietschel M, Holsboer F, Farmer AE, Craig IW, Scherer SW, McGuffin P: Genome-wide association analysis of copy number variation in recurrent depressive disorder. Mol Psychiatry 2013, 18:183-189.

5. Ripke $\mathrm{S}$, Wray NR, Lewis CM, Hamilton SP, Weissman MM, Breen G, Byrne EM, Blackwood DHR, Boomsma DI, Cichon S, Heath AC, Holsboer F, Lucae S, Madden PAF, Martin NG, McGuffin P, Muglia P, Noethen MM, Penninx BP, Pergadia ML, Potash JB, Rietschel M, Lin D, Müller-Myhsok B, Shi J, Steinberg S, Grabe HJ, Lichtenstein P, Magnusson P, Perlis RH, et al: A mega-analysis of genome-wide association studies for major depressive disorder. Mol Psychiatry 2012, 18:497-511.

6. Rucker JJH, McGuffin P: Polygenic heterogeneity: a complex model of genetic inheritance in psychiatric disorders. Biol Psychiatry 2010, 68:312-313.

7. Gottesman I, Shields J: A polygenic theory of schizophrenia. Proc Natl Acad Sci U S A 1967, 58:199-205.

8. Bushati N, Cohen SM: microRNA functions. Annu Rev Cell Dev Biol 2007, 23:175-205.

9. Turchinovich A, Weiz L, Langheinz A, Burwinkel B: Characterization of extracellular circulating microRNA. Nucleic Acids Res 2011, 39:7223-7233.

10. Lopez JP, Lim R, Cruceanu C, Crapper L, Fasano C, Labonte B, Maussion G, Yang JP, Yerko V, Vigneault E, El Mestikawy S, Mechawar N, Pavlidis P, Turecki G: miR-1202 is a primate-specific and brain-enriched microRNA involved in major depression and antidepressant treatment. Nat Med 2014, 20:764-768.

doi:10.1186/s13059-014-0421-3

Cite this article as: Rucker and McGuffin: Chipping away at major depressive disorder. Genome Biology 2014 15:421. 